\title{
Interleukin-6 in neuromyelitis optica spectrum disorder pathophysiology
}

Kazuo Fujihara, MD, Jeffrey L. Bennett, MD, PhD, Jerome de Seze, MD, PhD, Masayuki Haramura, PhD, Ingo Kleiter, MD, Brian G. Weinshenker, MD, Delene Kang, Tabasum Mughal, PhD, and

Takashi Yamamura, MD, PhD

Neurol Neuroimmunol Neuroinflamm 2020;7:e841. doi:10.1212/NXI.0000000000000841
Correspondence

Dr. Fujihara

fujikazu@med.tohoku.ac.jp

\begin{abstract}
Neuromyelitis optica spectrum disorder (NMOSD) is a rare autoimmune disorder that preferentially affects the spinal cord and optic nerve. Most patients with NMOSD experience severe relapses that lead to permanent neurologic disability; therefore, limiting frequency and severity of these attacks is the primary goal of disease management. Currently, patients are treated with immunosuppressants. Interleukin-6 (IL-6) is a pleiotropic cytokine that is significantly elevated in the serum and the CSF of patients with NMOSD. IL-6 may have multiple roles in NMOSD pathophysiology by promoting plasmablast survival, stimulating the production of antibodies against aquaporin-4, disrupting blood-brain barrier integrity and functionality, and enhancing proinflammatory T-lymphocyte differentiation and activation. Case series have shown decreased relapse rates following IL-6 receptor (IL-6R) blockade in patients with NMOSD, and 2 recent phase 3 randomized controlled trials confirmed that IL-6R inhibition reduces the risk of relapses in NMOSD. As such, inhibition of IL-6 activity represents a promising emerging therapy for the management of NMOSD manifestations. In this review, we summarize the role of IL-6 in the context of NMOSD.
\end{abstract}




\section{Glossary}

ADEM = acute disseminated encephalomyelitis; AQP4 = aquaporin-4; ARR = annualized relapse rate; $\mathbf{B B B}=$ blood-brain barrier; CD59 = complement regulatory protein; CDC = complement-dependent cytotoxicity; CDCC $=$ complementdependent cellular cytotoxicity; EDSS = Expanded Disability Status Scale; GFAP = glial fibrillary acidic protein; GRP78 = 78$\mathrm{kDa}$ glucose-regulated protein; HR = hazard ratio; ICAM-1 = intracellular adhesion molecule 1; IgG = immunoglobulin G; IL-6 = interleukin-6; IL-6R = interleukin-6 receptor; IPND = International Panel for NMO Diagnosis; LETM = longitudinal extensive transverse myelitis; MAC = membrane attack complex; mIL-6R = membrane-bound IL-6R; MOG = myelin oligodendrocyte glycoprotein; $\mathbf{M S}=$ multiple sclerosis; NF- $\mathbf{k B}=$ nuclear factor kappa-light-chain-enhancer of activated B cells; NMO = neuromyelitis optica; NMOSD = neuromyelitis optica spectrum disorder; $\mathbf{O N}=$ optic neuritis; SE = standard error; SEM = standard error of the mean; sgp130 = soluble glycoprotein 130; sIL-6R = soluble IL-6R; SLE = systemic lupus erythematosus; TGF- $\beta 1=$ transforming growth factor beta 1 ; $\mathbf{T h}=\mathrm{T}$ helper cell; $\mathbf{T r e g}=$ regulatory $\mathrm{T}$ cell .

Interleukin-6 (IL-6) is a soluble, pleiotropic cytokine that plays a key part in many biologic processes. ${ }^{1}$ It is a primary regulator of acute and chronic inflammation and hematopoiesis, contributing to the onset and maintenance of various autoimmune and inflammatory disorders. ${ }^{1}$

Neuromyelitis optica spectrum disorder (NMOSD) is an uncommon, often debilitating, inflammatory condition of the $\mathrm{CNS}^{2}{ }^{2}$ Neuromyelitis optica (NMO) was previously considered a rare, severe variant of multiple sclerosis (MS); however, it is now recognized as a distinct autoimmune disorder. ${ }^{2} \mathrm{An}$ International Panel for NMO Diagnosis codified clinical, radiologic, and laboratory features collectively distinguishing NMOSD from MS and other CNS inflammatory disorders. ${ }^{2}$ Left untreated, patients with NMOSD experience new attacks or relapses, often leading to permanent disability. ${ }^{3}$

The pathophysiologic processes and inflammatory cascade in NMOSD are complex and not fully understood. Circulating immunoglobulin $\mathrm{G}$ ( $\mathrm{IgG}) 1$ antibodies targeting the astrocyte water channel aquaporin-4 (AQP4) have been found almost exclusively in patients with NMOSD. ${ }^{3}$ AQP4-IgG binding to astrocytic AQP4 leads to classical complement cascade activation and granulocyte and lymphocyte infiltration that combine to damage neural tissues. ${ }^{4,5}$

IL-6 may drive disease activity in NMOSD by promoting plasmablast survival, stimulating AQP4-IgG secretion, reducing blood-brain barrier (BBB) integrity and functionality, and enhancing proinflammatory T-lymphocyte differentiation and activation (figure A). CSF and serum IL-6 levels are significantly elevated in patients with NMOSD, and IL-6 inhibition has been shown to improve disease control (table 1). Therefore, the IL-6 receptor (IL-6R) represents a promising therapeutic target for NMOSD relapse prevention. This review summarizes the role of IL-6 in NMOSD.

\section{Interleukin-6}

\section{Biological activities}

IL-6 is produced by diverse cell types, such as T cells, B cells, monocytes, fibroblasts, keratinocytes, endothelial cells, and mesangial cells. ${ }^{6} \mathrm{IL}-6$ is involved in many physiologic processes, including inflammation, antigen-specific immune responses, host defense mechanisms, hematopoiesis, and production of acute phase proteins. ${ }^{6}$ Outside the immune system, IL- 6 can promote angiogenesis, osteoclast differentiation, and keratinocyte and mesangial cell proliferation. ${ }^{7}$ Within the immune system, IL-6 plays a key part in the adaptive immune response by stimulating antibody production and effector $\mathrm{T}$-cell development. ${ }^{7}$ Furthermore, IL-6 has an important role in regulating the balance between proinflammatory $\mathrm{T}$ helper $(\mathrm{Th}) 17$ cells and regulatory T cells (Treg). ${ }^{7}$

IL-6 binds to the IL-6 receptor (IL-6R), which is expressed as membrane-bound (mIL-6R) and soluble (sIL-6R) forms. ${ }^{8}$ The sIL-6R binds to IL-6 with a similar affinity as the $\mathrm{mIL}-6 \mathrm{R}$, and both receptors interact with glycoprotein 130 (gp130, also known as IL$6 \mathrm{R}$ subunit $\beta$ ) to initiate cellular signaling through the Src homology region 2-containing protein tyrosine phosphatase-2/ mitogen-activated protein kinase and Janus kinase/signal transducer and activator of transcription 3 protein pathways (figure $B$ ). ${ }^{8}$ Importantly, cells that do not express IL-6R and are therefore not responsive to IL- 6 can be stimulated by the complex of sIL-6R-IL6 (IL-6 trans-signaling). IL-6 trans-signaling can be selectively blocked by the soluble form of gp 130 (sgp130Fc) - which is dimerized by a human immunoglobulin IgG1-Fc - without affecting $\mathrm{IL}-6$ signaling via the membrane-bound $\mathrm{IL}-6 \mathrm{R}^{8}$

\section{Pathogenic role}

Dysregulation of IL-6 expression or signaling contributes to the pathogenesis of various human diseases and is linked to inflammatory and/or lymphoproliferative disorders, such as rheumatoid arthritis, Castleman disease, multiple myeloma, giant cell arteritis, and systemic lupus erythematosus (SLE). ${ }^{8}$ The pathways driving IL-6 secretion from CNS-resident cells are complex. Neurons, astrocytes, microglia, and endothelial cells produce IL-6 following injury, and CSF IL-6 levels are elevated in multiple neuroinflammatory diseases. ${ }^{9}$

Dysregulation of IL-6 signaling may aggravate the inflammatory response in some CNS diseases; however, intrathecal IL-6 production may have variable effects. Because the IL-6R is expressed on both oligodendrocyte progenitor cells and microglia, CNS IL6 signaling may have both direct and indirect effects on 


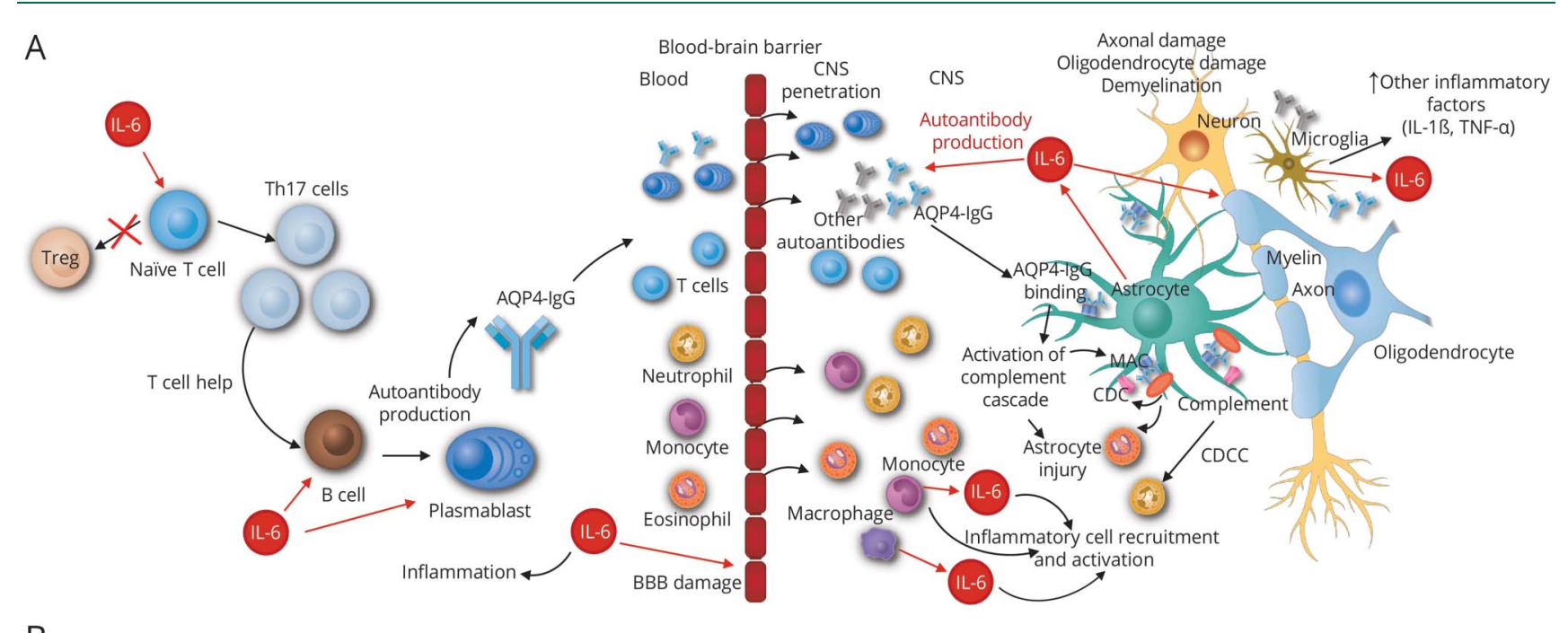

B

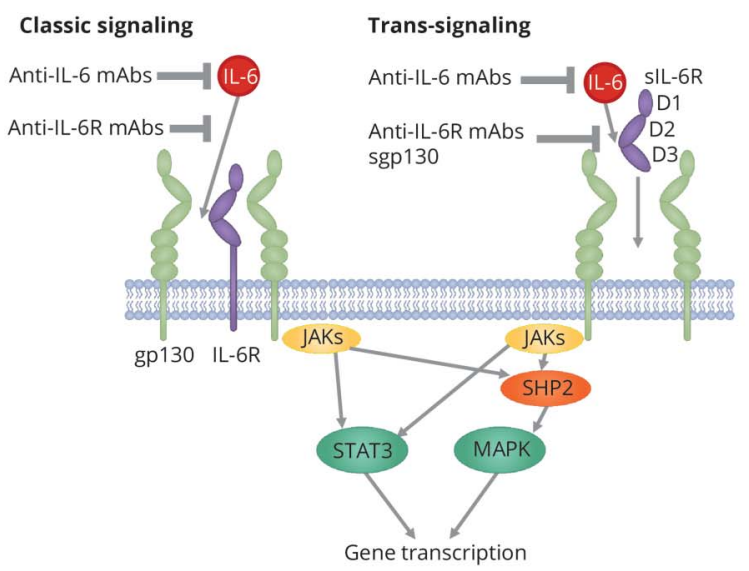

(A) Potential roles for IL-6 signaling in NMOSD pathophysiology. IL-6 induces differentiation of inflammatory Th17 cells from naive T cells, which in turn provide support to AQP4-dependent activated B cells. IL-6 also promotes differentiation of B cells into plasmablasts, inducing production of pathogenic AQP4-IgG. These events are followed by increased BBB permeability to antibodies and proinflammatory cell infiltration into the CNS, leading to binding of AQP4-IgG to AQP4 channels on the astrocytes. In response to stimulation by proinflammatory cytokines, astrocytes produce IL-6, which promotes demyelination and contributes to oligodendrocyte and axon damage. (B) Schematic of IL-6 signaling with potential modes of therapeutic inhibition. IL-6 can bind either to the membrane-bound (classic signaling) or soluble form (transsignaling) of the IL-6R a receptor. IL-6 trans-signaling allows for the activation of cells that do not express the IL-6R a receptor. Classic signaling may be blocked by antibodies against IL-6 and IL-6R. Trans-signaling may be blocked by antibodies against IL-6R or the soluble form of glycoprotein 130 (sgp130). IL-6 signaling is mediated at the plasma membrane through the homodimerization of gp130, which activates the intracellular JAK-STAT and SHP2-MAPK signaling pathways. AQP4 = aquaporin-4; AQP4-IgG = aquaporin-4 immunoglobulin G; BBB = blood-brain barrier; CDC = complement-dependent cytotoxicity; CDCC = complement-dependent cellular cytotoxicity; D1-D3 = subdomain of IL-6Ra; IL-1 $\beta$ = interleukin-1 $\beta$; IL-6 = interleukin-6; JAK/STAT = Janus kinase/signal transducers and activators of transcription; MAC = membrane attack complex; mAbs = monoclonal antibodies; $\mathrm{MAPK}=$ mitogen-activated protein kinase; NMOSD = neuromyelitis optica spectrum disorder; sgp130 = soluble glycoprotein 130; SHP2/MAPK = Src homology region 2 domain-containing phosphatase-2/mitogen-activated protein kinase; STAT3 = signal transducers and activators of transcription 3; Th = T helper cell; TNF- $\mathrm{a}=$ tumor necrosis factor $\mathrm{a}$; Treg = regulatory $\mathrm{T}$ cell.

microglial and macroglial survival. In rat cerebral ischemic injury, it was shown that IL-6 modulates a decrease in neuronal and $\mathrm{BBB}$ integrity in the CNS. ${ }^{10}$ In addition, intrathecal IL-6 production during CNS inflammation has been demonstrated to affect BBB permeability. ${ }^{11}$ How these roles interact to promote CNS injury in autoimmune disease requires further research.

\section{Neuromyelitis optica spectrum disorder}

\section{Overview}

NMOSD is a rare, debilitating, autoimmune condition of the CNS, characterized by inflammatory lesions predominantly in the spinal cord and optic nerves. ${ }^{4} \mathrm{~Pa}-$ tients with NMOSD may present with a variety of symptoms, but most commonly with optic neuritis and myelitis. Optic neuritis or the inflammation of the contiguous optic chiasm causes acute visual impairment and eye pain. Myelitis causes varying degrees of motor paralysis, sensory loss, pain, or bladder and bowel dysfunction associated with MRI evidence of longitudinal extensive transverse myelitis (LETM) lesions. NMOSD may also lead to intractable hiccups, nausea, or vomiting due to area postrema lesion inflammation; brainstem dysfunction; or encephalopathy. ${ }^{12}$ Most patients with NMOSD experience a more severe disease course than do patients with MS due to 
Table 1 Clinical case reports on IL-6R blockade in the treatment of patients with NMOSDa

\begin{tabular}{|c|c|c|c|c|c|}
\hline Case No. & Age (y)/sex & DD (y) & $\begin{array}{l}\text { ARR (IL-6 block) } \\
\text { before/during }\end{array}$ & Other effects of anti-IL-6 & AEs associated with anti-IL-6 \\
\hline $1^{54}$ & $31 / F$ & 12.1 & $1.6 / 0.5$ & No new or active SL (47 months) & $\begin{array}{l}\text { Transient diarrhea, deep venous } \\
\text { thrombosis }\end{array}$ \\
\hline $2^{54}$ & $18 / F$ & 8.8 & $2.1 / 0.3$ & No new or active SL (33 months) & R-UTI during self-catheterization \\
\hline $3^{54}$ & $30 / F$ & 5.5 & $2.5 / 0$ & No new or active SL (41 months) & None \\
\hline $4^{54}$ & $37 / F$ & 2.8 & $1.8 / 0.6$ & No new or active SL (34 months) & Headache, fatigue \\
\hline $5^{54}$ & $22 / F$ & 8.9 & $1.2 / 0$ & No new or SL (28 months) & None \\
\hline $6^{54}$ & $24 / F$ & 24 & $0.7 / 0$ & No new but still active SL (14 months) & Transient mild fatigue \\
\hline $7^{54}$ & $24 / F$ & 0.9 & $5.5 / 0.8$ & No new or active SL (12 months) & $\begin{array}{l}\text { Mild post-infusion nausea, transient } \\
\text { gastritis, R-UTI }\end{array}$ \\
\hline $8^{54}$ & $49 / F$ & 0.5 & $6 / 2.4$ & No new or active SL (3 months) & R-UTI \\
\hline $9^{55}$ & $32 / F$ & 8.8 & $1.3^{\mathrm{b}} / 0$ & $\begin{array}{l}\text { EDSS score: } 9.0 \text { to } 2.5 \text {. Anti-AQP4-Ab } \\
\text { titer dropped from } 1: 800 \text { to } 1: 20\end{array}$ & None \\
\hline $10^{56}$ & $37 / F$ & 14 & $3 / 1.5^{b}$ & Oral PSL and AZA were tapered & $\begin{array}{l}\text { URIs, AEC, acute pyelonephritis, LKP } \\
\text { and/or LPP }\end{array}$ \\
\hline $11^{56}$ & $38 / \mathrm{F}$ & 11 & $2 / 0$ & NA & NA \\
\hline $12^{56}$ & $26 / F$ & 5 & $2 / 0$ & Oral PSL was tapered & Anemia \\
\hline $13^{56}$ & $31 / \mathrm{M}$ & 19 & $2 / 0$ & Oral PSL and AZA were tapered & AEC, LKP and/or LPP \\
\hline $14^{56}$ & $55 / F$ & 17 & $3 / 0.77^{b}$ & NA & NA \\
\hline $15^{56}$ & $62 / F$ & 2 & $3 / 0$ & NA & NA \\
\hline $16^{56}$ & $23 / F$ & 2 & $5 / 0$ & Oral PSL was tapered & URIs, LKP and/or LPP, anemia \\
\hline $17^{57}$ & $36 / F$ & 1.7 & $4.3^{\mathrm{b}} / 0$ & $\begin{array}{l}\text { EDSS score: } 8.0 \text { to } 2.5 \text {. MRI has } \\
\text { remained free of Gd activity }\end{array}$ & No safety signals have occurred \\
\hline $18^{\mathrm{c}, \mathrm{d}, 58}$ & $40 / F$ & 9.4 & $2.6 / 0.6$ & $\begin{array}{l}\text { EDSS score: } 6.5 \text { to } 6.5 \text {. No new } \\
\text { lesions, no contrast enhancement }\end{array}$ & No serious AEs were observed \\
\hline $19^{c, d, 58}$ & $26 / F$ & 8.2 & $2.7 / 0$ & $\begin{array}{l}\text { EDSS score: } 5.0 \text { to } 4.0 \text {. No new } \\
\text { lesions, no contrast enhancement }\end{array}$ & No serious AEs were observed \\
\hline $20^{c, d, 58}$ & $39 / F$ & 2.5 & $1.7 / 1.3$ & $\begin{array}{l}\text { No new lesions, no contrast } \\
\text { enhancement }\end{array}$ & $\begin{array}{l}\text { UTI. Mild oral mucosis. No } \\
\text { serious AEs }\end{array}$ \\
\hline $21^{c, 59}$ & $36 / F$ & 14 & $5.3^{b} / 2^{b}$ & $\begin{array}{l}\text { EDSS score: improved from } 3.5 \text { to } 2.0 \text {. } \\
\text { No significant changes of lesions on MRI }\end{array}$ & $\begin{array}{l}\text { Decline in systolic blood pressure. LPP. } \\
\text { Enteritis caused by a norovirus. A URI }\end{array}$ \\
\hline \multicolumn{6}{|c|}{$\begin{array}{l}\text { Abbreviations: } \mathrm{AE}=\text { adverse event; } \mathrm{AEC}=\text { acute enterocolitis; } \mathrm{AZA}=\text { azathioprine; } \mathrm{CS}=\mathrm{CC} \\
\text { leukocytopenia; } \mathrm{LPP}=\text { lymphocytopenia; } \mathrm{NA}=\text { not applicable; } \mathrm{PSL}=\text { prednisolone; } \\
\mathrm{SL}=\text { spinal lesions; URI = upper respiratory infection. } \\
\text { All patients are serum AQP4-IgG positive. } \\
\text { a Please see the supplemental table (links.Iww.com/NXI/A288) for full version of the table. } \\
\text { b Calculated from the number of relapses, please see the supplemental table. } \\
\text { ' No oligoclonal IgG bands found. } \\
\text { d No concomitant autoimmune diseases. }\end{array}$} \\
\hline
\end{tabular}

frequent and severe relapses that lead to early and incremental disability. A benign disease course of NMOSD is rare. ${ }^{13}$ Limiting frequency and severity of relapses represents a primary goal in NMOSD management. ${ }^{14}$

If patients are not treated, $49 \%$ and $70 \%$ of patients relapse within 1 and 2 years, respectively. ${ }^{15}$ The mean annualized relapse rate (ARR) in patient cohorts ranges from 0.82 to 1.34 , with a median time to first relapse of 14 months. ${ }^{15}$ The mortality rate without treatment ranges from $9 \%$ to
$32 \%$, depending on age, relapse rate, and recovery from attacks. $^{16}$

In 2004, the identification of AQP4-IgG greatly facilitated differentiation of NMO from MS, ${ }^{17}$ and in 2006, AQP4-IgG serology was incorporated into the revised NMO diagnostic criteria. ${ }^{18}$ An international expert panel in 2015 proposed a unifying term for the disease as NMOSD, with further stratification by AQP4-IgG serologic status. ${ }^{2}$ 


\section{Pathophysiology}

NMOSD is recognized as a humoral immune disease driven in most patients by the presence of AQP4-IgG. ${ }^{19}$ As a result, initial attention has focused on B-cell autoimmunity in NMOSD. However, polymorphonuclear infiltration into the CNS is a prominent feature of active disease and is characteristic of Th17-mediated pathology. ${ }^{20}$ Furthermore, clinical worsening in response to interferon- $\beta$ therapy in patients with NMOSD is also characteristic of Th17-mediated inflammatory processes. Thus, T-cell autoimmunity may also play a part in disease pathogenesis. ${ }^{20}$

\section{Role of AQP4}

AQP4 is the most abundant water channel in the CNS and has a key role in transcellular water transport. ${ }^{21} \mathrm{AQP} 4$ function may also affect neuroinflammation, astrocyte migration, and neuroexcitation. Within the CNS, AQP4 is expressed in the endfeet of astrocytes that surround the blood vessels and subarachnoid space and in retinal Mueller cells. It is particularly enriched in brain parenchyma interfacing with the CSF. ${ }^{21}$

AQP4-IgG has a critical role in mediating CNS injury in NMOSD. AQP4-IgG is detected in $\sim 70 \%$ of patients with NMOSD, but not in patients with MS or other neurologic diseases. ${ }^{22}$ In AQP4-IgG-seropositive patients with NMOSD, CNS injury initiates with the binding of AQP4-IgG to AQP4 on perivascular astrocyte endfeet. ${ }^{4}$ Autoantibody binding results in activation of the classical complement cascade, granulocyte and macrophage infiltration, secondary oligodendrocyte damage, and neuronal death. ${ }^{4}$ CSF analysis of patients with NMOSD suggests that the majority of AQP4-IgG may transit passively to the CNS through an open BBB. ${ }^{22}$ However, molecular techniques show that AQP4-IgG is also produced intrathecally during acute NMOSD exacerbations. ${ }^{23}$

Whether AQP4-IgG-seronegative patients with NMOSD have the same disease as AQP4-IgG-seropositive patients remains controversial. The demographics, clinical presentation, and prognosis differ between AQP4-IgG-seropositive and AQP4IgG-seronegative patients. ${ }^{24}$ Some AQP4-IgG-seronegative patients are seropositive for myelin oligodendrocyte glycoprotein (MOG)-IgG; however, MOG-IgG-seropositive patients show differences in natural history, neuroimaging, and lesion histopathology from AQP4-IgG-seropositive patients, supporting a distinct pathophysiology between these disorders. $^{25}$

\section{Role of the BBB}

Disruption of the BBB is important in the pathophysiology of NMOSD and correlates modestly with disease activity. Intrathecal production of AQP4-IgG ${ }^{23}$ may initiate disease activity by causing focal $\mathrm{BBB}$ breakdown and precipitating a large influx of serum AQP4-IgG and serum complement into the CNS compartment. Alternatively, systemic inflammation may disrupt the BBB, allowing entry of serum AQP4-IgG and autoreactive $\mathrm{B}$ cells into the CNS and subsequent lesion formation. ${ }^{19}$
A recent study demonstrated that some serum samples taken from patients with NMOSD and SLE harbor autoantibodies against the 78-kDa glucose-regulated protein (GRP78-IgG). These autoantibodies bind to brain microvascular endothelial cells, resulting in nuclear factor kappa-light-chain-enhancer of activated B-cell nuclear translocation, intercellular adhesion molecule 1 induction, reduced tight junction expression, and barrier permeability. ${ }^{26}$ Peripheral administration of recombinant GRP78-IgG to mice resulted in increased BBB permeability, suggesting that GRP78 autoantibodies may induce BBB permeability and may contribute to disease activity in some patients. ${ }^{26}$ Further research is needed to confirm whether GRP78-IgG has a role in NMOSD pathogenesis.

\section{Role of complement}

Complement activation plays an essential part in NMOSD lesion formation. ${ }^{4}$ Activation of the classical complement cascade is thought to result from engagement of complement component $\mathrm{Clq}$ with $\mathrm{AQP} 4-\mathrm{IgG}$ bound to perivascular astrocyte endfeet. ${ }^{4}$ This leads to classical complement cascade activation and membrane attack complex formation. ${ }^{4}$

Nytrova et al. showed that levels of the complement component $\mathrm{C} 3 \mathrm{a}$ were higher in patients with NMO than in healthy control subjects and that $\mathrm{C} 3 \mathrm{a}$ levels in these patients also correlated with disease activity, neurologic disability, and AQP4-IgG. ${ }^{27}$

Recent in vitro studies have identified alternative complement pathways, such as the bystander mechanism, where, following AQP4-IgG binding to astrocyte AQP4, activated, soluble complement proteins were implicated in early oligodendrocyte injury in NMOSD. ${ }^{28}$ In addition, complement regulatory protein (CD59) may confer a protective role in AQP4IgG-seropositive NMOSD tissues outside of the CNS and thus explain why peripheral AQP4-expressing cells in NMOSD remain mostly unaffected. ${ }^{29}$

\section{Relationship between gut microbiota and humoral and cellular immunity}

The AQP4 epitope p63-76 displays sequence homology with p204-217 of Clostridium perfringens, a ubiquitous Grampositive bacterium found in the human gut. ${ }^{30}$ This observation provided new perspectives for investigating NMOSD pathogenesis. Gut microbiome analysis of patients with NMO identified an overabundance of $C$. perfringens. ${ }^{30}$ Because specific gut clostridia can regulate Treg and Th17 cell balance, ${ }^{31}$ an excess of $C$. perfringens could theoretically evoke proinflammatory AQP4-specific T- and B-cell responses driving NMOSD development. C. perfringens may also enhance Th17 differentiation by promoting the secretion of IL- 6 by antigenpresenting cells in the gut. ${ }^{30}$

\section{Pathophysiologic role of IL- 6}

IL-6 levels are associated with key NMOSD disease markers. ${ }^{32,33}$ Studies have shown that CSF and serum levels of IL-6 correlate with CSF cell counts and the Expanded Disability 


\begin{tabular}{|c|c|c|c|c|c|c|c|c|}
\hline Reference & $\mathbf{N}$ & Female, $\mathbf{n}$ & $\begin{array}{l}\text { CSF cell count, } \\
\text { cells } / \mathrm{mm}^{3}\end{array}$ & $\begin{array}{l}\text { Mean (SD) CSF IL-6 } \\
\text { levels, pg/mL }\end{array}$ & $\begin{array}{l}\rho(p \text { value) between } \\
\text { IL-6 levels and CSF cell count }\end{array}$ & $\begin{array}{l}\text { Mean (SD) serum } \\
\text { IL-6 levels, pg/mL }\end{array}$ & $\begin{array}{l}\text { Baseline EDSS } \\
\text { score, mean (SD) }\end{array}$ & $\begin{array}{l}\rho(p \text { value) correlation between } \\
\text { IL-6 levels and EDSS score }\end{array}$ \\
\hline Wang et al. ${ }^{33}$ & 22 & 16 & NR & $24.95(25.57)$ & NR & NR & $3.5(1.0-8.5)^{a}$ & $0.372(0.088)^{\mathrm{b}}$ \\
\hline Uzawa et al. ${ }^{34}$ & 31 & 31 & 26.8 & $757.3(1179.6)$ & $0.638(<0.001)$ & NR & $7.5(2.0-9.0)^{a}$ & $0.258(0.161)^{\mathrm{b}}$ \\
\hline Uchida et al. ${ }^{35}$ & 29 & 27 & $8(12.0)^{a, c}$ & $89.3(737.7)^{a}$ & $0.4497(0.021)$ & $2.32(0.00)^{d}$ & $6.0(3)^{a}$ & NR \\
\hline Matsushita et al. ${ }^{36}$ & 20 & 17 & $11.5(15.3)^{\mathrm{e}}$ & NR & $0.75(0.012)$ & NR & $5.6(2.5)$ & $0.72(0.012)^{b}$ \\
\hline Icoz et al. ${ }^{37}$ & 23 & 17 & & & & & & \\
\hline AQP4-IgG+ & 12 & 10 & $12^{f}(3.63)^{g}$ & $781^{f}(207.98)^{g}$ & NR & $48^{f}(9.44)^{g}$ & $6^{f}(0.73)^{g}$ & NR \\
\hline AQP4-IgG- & 11 & 7 & $18^{f}(3.41)^{g}$ & $39^{f}(15.64)^{g}$ & NR & $11^{f}(4.11)^{g}$ & $4^{f}(0.59)^{g}$ & NR \\
\hline Barros et al. ${ }^{38}$ & 20 & 16 & NR & NR & NR & $\begin{array}{l}514.1(213.1)^{\mathrm{h}} \\
898.4(411)^{\mathrm{k}}\end{array}$ & $4.93(1.91)^{i}$ & $0.5880(0.0064)^{j}$ \\
\hline Uzawa et al. ${ }^{39}$ & 17 & 17 & 9.5 & $281.0(212.4)^{g}$ & $0.5(0.002)$ & NR & NR & NR \\
\hline \multicolumn{9}{|c|}{$\begin{array}{l}\text { Abbreviations: AQP4-IgG = aquaporin-4-immunoglobulin G; EDSS = Expanded Disability Status Scale; IL-6 } \\
\text { a Median (interquartile range). } \\
\text { b In CSF. } \\
\text { c/ } / \mu \text { L. } \\
\text { d } n=29 . \\
\text { e } n=19 \text {. } \\
{ }^{f} \text { Mean/median not specified. } \\
\text { g Mean (standard error). } \\
\text { h Patients who did not relapse. } \\
\text { i The EDSS score was determined either at the time the blood was analyzed or after } 2 \text { years of follow-up. } \\
\text { j In plasma. } \\
\text { k Patients who relapsed. }\end{array}$} \\
\hline
\end{tabular}


Status Scale (EDSS) score (table 2). ${ }^{33-39}$ CSF levels of IL-6 are shown to correlate with AQP4-IgG levels and glial fibrillary acidic protein levels, an indicator of astrocyte damage. ${ }^{34} \mathrm{CSF}$ and serum IL- 6 concentrations are significantly elevated in patients with NMOSD and are higher than in healthy individuals and patients with MS or other noninflammatory neurologic disorders. ${ }^{34-37}$ In 1 study, an IL-6 CSF concentration of $7.8 \mathrm{pg} / \mathrm{mL}$ was proposed as an optimal cutoff value for diagnosing NMOSD. ${ }^{32}$ Furthermore, CSF IL-6 levels are also significantly elevated in the acute phase of NMOSD compared with MS, myelitis, ON, and other inflammatory and noninflammatory neurologic disorders. ${ }^{40}$ IL- 6 levels may be indicative of NMOSD relapse because IL-6 serum and CSF concentrations in patients with NMOSD are significantly higher during relapse than in periods of remission. ${ }^{36,38}$

Barros et al. also demonstrated a relationship between serum IL-6 levels with occurrence of clinical relapses in patients with NMO. ${ }^{38}$ Furthermore, during a 2-year disease follow-up in these patients, baseline IL-6 levels correlated with the risk of clinical relapses and severity. An 8-fold increase in relapse risk was observed in patients with IL-6 serum concentrations above the baseline median value of $58.5 \mathrm{pg} / \mathrm{mL}$ during remissions. ${ }^{38}$

Higher IL-6 levels are also associated with greater disability in NMOSD following relapse. One study evaluated recovery from relapse-related impairment in patients with NMOSD and demonstrated that patients with NMOSD and higher CSF IL-6 levels experienced more modest improvements than did patients with lower IL-6 levels. ${ }^{41}$ Furthermore, elevated IL-6 levels have been linked with short relapse-free durations in NMOSD after relapse. Uzawa et al. ${ }^{41}$ evaluated the relapse-free duration after relapse in patients with NMOSD and found that patients with high CSF IL-6 levels tended to have shorter relapse-free durations than did those with low IL-6 levels following relapse $(p=0.079)$.

\section{Effect of IL-6 on B cells}

B cells appear to have a central proinflammatory role in NMOSD immunopathology. ${ }^{19}$ This is mediated through several proposed mechanisms, including production of AQP4-IgG, antigen presentation, increased B-cell and plasmablast activity, and reduced regulatory function of B cells. ${ }^{19}$

IL-6 was originally identified as B cell stimulatory factor-2, which induced activated B cells into antibody-producing cells. ${ }^{7}$ Indeed, circulating short-lived, $\mathrm{CD} 19^{\text {int }} \mathrm{CD} 27^{\text {high }} \mathrm{CD} 38^{\text {high }} \mathrm{CD} 180^{-}$ plasmablasts may be increased in the peripheral blood of some patients with NMOSD and are capable of producing AQP4-IgG when stimulated with $\mathrm{IL}-6 .{ }^{42}$ However, these activated antibodysecreting cells may not play a major part in the maintenance of circulating serum AQP4-IgG. Detailed molecular studies have demonstrated that $\mathrm{AQP} 4$-specific, peripheral blood $\mathrm{B}$ cells in the $\mathrm{CD} 27^{+}$classical and $\mathrm{CD} 27^{-}$IgD memory compartments show the closest lineal relationship to AQP4-IgG-secreting cells in the $\mathrm{CSF}^{43}$ In addition, human cell culture experiments showed that AQP4-IgG-secreting cells were readily generated from pregerminal center-naive and postgerminal center memory $\mathrm{B}$ cells, but not the circulating plasmablast compartment. IL-6R blockade may act indirectly to modulate AQP4-IgG production and relapse risk through its effects on T-cell development. ${ }^{44}$ Further immunologic studies of serum AQP4-IgG titers and circulating B-cell profiles via $\mathrm{T}$-cell development in patients with NMOSD receiving $\mathrm{IL}-6 \mathrm{R}$ inhibitors are needed.

\section{Effect of IL-6 on T cells}

Naive $\mathrm{T}$ cells are differentiated into Th17 cells through the combination of transforming growth factor beta 1 (TGF- $\beta 1$ ), IL-6, and IL-23. ${ }^{45}$ Th17 cells mediate disruption of the BBB and subsequent CNS inflammation. ${ }^{45}$ Levels of Th17-related cytokines, $\mathrm{IL}-17$, $\mathrm{IL}-21$, and $\mathrm{IL}-23$ are increased in NMOSD, as is the level of IL-6, particularly in AQP4-IgG-seropositive patients with NMOSD. ${ }^{46}$ AQP4-specific $T$ cells in AQP4IgG-seropositive patients with NMO exhibit Th17 polarization. ${ }^{47}$ In addition, levels of Th17-related cytokines, including $\mathrm{IL}$ 6, are significantly elevated in the CSF and peripheral blood of patients with NMOSD during relapse. ${ }^{34}$ The release of IL- 6 and other Th17-related cytokines by activated $\mathrm{T}$ lymphocytes from patients with NMOSD was also found to directly correlate with neurologic disability and risk of relapse. ${ }^{34,38}$

\section{Effect of IL- 6 in the BBB}

Proinflammatory cytokines, including IL-6, increase the permeability of the BBB allowing antibodies and proinflammatory cells to infiltrate the CNS, leading to binding of AQP4-IgG to AQP4 channels on the astrocytes. In response to stimulation by proinflammatory cytokines, astrocytes produce IL-6, which promotes demyelination and contributes to oligodendrocyte and axon damage (figure A). In vitro BBB models, including cocultures of human brain microvascular endothelial cells and human astrocyte cell lines with or without AQP4 expression, showed that AQP4-IgG induced IL-6 production by AQP4-positive astrocytes, and IL-6 signaling to endothelial cells impaired BBB function, increased production of other chemokines, and enhanced flow-based leukocyte transmigration. ${ }^{48}$ These effects were reversed with an IL-6R-neutralizing antibody. ${ }^{48}$

\section{MOG-IgG-seropositive patients and IL-6}

MOG is a glycoprotein localized on the surface of the myelin sheath and represents a potential target for the treatment of demyelinating diseases. Mice immunized with MOG peptides may develop experimental autoimmune encephalomyelitis with an NMO phenotype. MOG-IgG is found in a subset of patients with optic neuritis, acute disseminated encephalomyelitis/ multiphasic disseminated encephalomyelitis, myelitis, AQP4IgG-seronegative NMOSD, or encephalitis. ${ }^{49}$ Although MOGIgG-seropositive and AQP4-IgG-seropositive NMOSD share a similar serum and CSF cytokine profile characterized by the coordinated upregulation of multiple cytokines, especially Th17related, these diseases have different pathologies. ${ }^{50}$ AQP4IgG-seropositive NMOSD is primarily an astrocytopathic disease, whereas MOG-IgG-seropositive NMOSD is a demyelinating disease. ${ }^{50}$ 


\section{Therapeutic approaches}

Current clinical practice involves treatment of exacerbations with high-dose corticosteroids, apheresis therapies, and off-label use of immunotherapies for relapse prevention, particularly with azathioprine, methotrexate, and prednisone (immunosuppressants); mycophenolate mofetil (inhibits lymphocyte proliferation); anti-CD20 monoclonal antibody; and anti-IL-6R monoclonal antibody. Until recently, NMO/NMOSD treatment studies were mostly retrospective.

There is a need for alternative therapeutic options for patients with NMOSD who do not respond to first-line therapy and for treatments that manage other manifestations of the disease, including pain and fatigue. Different therapeutic targets have been investigated in international randomized controlled trials. These include monoclonal antibodies targeting the B-cell antigen CD19 (inebilizumab), ${ }^{51} \mathrm{CD} 20$ (rituximab), the complement component 5 (eculizumab), ${ }^{52}$ and IL-6R (satralizumab). ${ }^{53}$

\section{IL-6 blockade in the treatment of NMOSD}

Targeting the IL-6 signaling pathway inhibits both the humoral immune response as well as T-cell pathway and dysfunction of the BBB, providing a comprehensive treatment for the different NMOSD manifestations. Several case reports showed decreased relapse rate and reduced neurologic disability following off-label treatment with an anti-IL-6R antibody in patients with NMOSD (table 1). ${ }^{54-59}$

Araki et al. ${ }^{56}$ reported that the mean (standard error of the mean [SEM]) ARR decreased from 2.9 (1.1) to 0.4 (0.8; $p<0.005$ ) and mean EDSS scores (SEM, range) from 5.1 (1.7, 3.0-6.5) to 4.1 (1.6, 2.0-6.0), following 12-month treatment with an anti-IL-6R antibody as add-on therapy to either prednisolone or immunosuppressants in 7 patients with NMOSD. In the same report, mean (SEM) pain decreased from 3.0 (1.5) at baseline to $0.9(1.2)$ at 12 months, and mean (SEM) general fatigue decreased from 6.1 (2.0) at baseline to 3.0 (1.4) at 12 months, respectively. Adverse events in this report included upper respiratory infections (2 patients), acute enterocolitis ( 2 patients), acute pyelonephritis (1 patient), leukocytopenia and/or lymphocytopenia (3 patients), anemia ( 2 patients), and a slight decline in systolic blood pressure ( 1 patient). However, none of the events were severe.

Ringelstein et al. ${ }^{54}$ reported that patients with NMOSD who were not responsive to rituximab and other immunosuppressants experienced significant improvements in the median ARR (from 4.0 at baseline to 0.4 at the end of the study, $p=0.008$ ), EDSS score (from 7.3 at baseline to 5.5 at the end of the study, $p=0.03$ ), and pain scores (from 6.5 at baseline to 2.5 at the end of the study, $p=0.02$ ) following treatment with an anti-IL-6R antibody. No major adverse events or laboratory abnormalities were reported except for elevation of cholesterol levels in 6 patients and neutropenia in 1 patient. $^{54}$ Similarly, Ayzenberg et al. reported that 3
AQP4-positive female patients with NMO and a history of treatment with rituximab and other immunosuppressive and immunomodulating agents experienced a reduction in median ARR (from 3.0 at baseline to 0.6 at the end of the study), but not in impairment scores after switching to an anti-IL-6R antibody. ${ }^{58}$ There was no serious infection, malignancy, hypersensitivity reaction, or elevation of transaminase levels. One patient experienced urinary tract infection in the fourth month and mild oral mycosis in the seventh month of therapy. ${ }^{58}$

Harmel et al. ${ }^{60}$ reported favorable outcomes following treatment with an anti-IL-6R antibody after inadequate response to interferon- $\beta$ therapy in a patient misdiagnosed with MS. Under interferon- $\beta$ treatment, the patient showed persisting relapse activity. Treatment with rituximab was initiated, but severe LETM attacks occurred shortly after. Following switch to an anti-IL-6R antibody, the patient experienced no further relapses for the following 12 months. Other single patient reports included no adverse events during treatment.

Satralizumab is a novel, humanized IgG2 recycling monoclonal antibody targeting the IL-6R. It has been investigated in 2 phase 3 studies for the treatment of NMOSD. ${ }^{53,61}$ Both results from the monotherapy trial (no other chronic baseline immunosuppression allowed) and data from the add-on to other immunosuppressive therapy trial were recently published. ${ }^{53,61}$ Satralizumab as an add-on to baseline treatment significantly reduced the risk of protocol-defined relapse by $62 \%$ vs placebo; hazard ratio (HR) 0.38 ; $95 \%$ CI $0.16-0.88 ; p=0.02$. Prespecified additional analyses showed a $79 \%$ relapse risk reduction with satralizumab vs placebo in AQP4-IgG-seropositive patients $(\mathrm{n}=55$; HR 0.21 ; 95\% CI $0.06-0.75)$ and $34 \%$ in AQP4-IgG-seronegative patients (HR 0.66; 95\% CI 0.20-2.24). In the overall study population, the ARR was 0.11 (95\% CI 0.05-0.21) when treated with satralizumab vs 0.32 (95\% CI $0.19-0.51)$ with placebo. There were no deaths or anaphylactic reactions in either group during the double-blind period. The rate of serious adverse events and infections did not differ between the satralizumab and placebo groups (table 3 ). ${ }^{53}$ The results of the monotherapy trial were similar to the results of the addon therapy trial (table 3). ${ }^{61}$ These results further support an important role of IL-6 in NMOSD pathophysiology.

\section{Summary and future directions}

NMOSD is recognized as a $\mathrm{B}$ - and $\mathrm{T}$-cell-mediated immune disease. IL-6 appears to have a key role in the immune response by stimulating antibody production in $\mathrm{B}$ cells and the development of effector $\mathrm{T}$ cells, by disruption of $\mathrm{BBB}$ function, and by regulating the balance between Th17 and Treg cells. Inhibition of IL-6 activity was shown to be effective in 2 phase 3 clinical trials, particularly in AQP4IgG-seropositive individuals, and represents a promising emerging therapy for the management of NMOSD. 


\begin{tabular}{|c|c|c|c|c|c|c|c|c|}
\hline Product name & \multicolumn{8}{|c|}{ Satralizumab } \\
\hline Mode of action & \multicolumn{8}{|c|}{ IL-6 inhibition (anti-IL-6 receptor monoclonal antibody) } \\
\hline Study name & \multicolumn{4}{|c|}{ SAkuraSky (NCT02028884) } & \multicolumn{4}{|c|}{ SAkuraStar (NCT02073279) } \\
\hline \multirow[t]{2}{*}{ Study design } & \multicolumn{4}{|c|}{$\begin{array}{l}\text { Add-on therapy to baseline } \\
\text { treatment; azathioprine, } \\
\text { mycophenolate mofetil, } \\
\text { and/or OCs compared with placebo }\end{array}$} & \multicolumn{4}{|c|}{ Monotherapy compared with placebo } \\
\hline & \multicolumn{4}{|c|}{ Every 4 wk, subcutaneously } & \multicolumn{4}{|c|}{ Every 4 wk, subcutaneously } \\
\hline Administration & \multicolumn{2}{|c|}{$\begin{array}{l}\text { Satralizumab } \\
(n=41)\end{array}$} & \multicolumn{2}{|l|}{$\begin{array}{l}\text { Placebo } \\
(n=42)\end{array}$} & \multicolumn{2}{|l|}{$\begin{array}{l}\text { Satralizumab } \\
(n=63)\end{array}$} & \multicolumn{2}{|l|}{$\begin{array}{l}\text { Placebo } \\
(\mathrm{n}=32)\end{array}$} \\
\hline \multicolumn{9}{|l|}{$\begin{array}{l}\text { Characteristics of the patient } \\
\text { at baseline }\end{array}$} \\
\hline Mean age, y (range) & \multicolumn{2}{|c|}{$40.8 \pm 16.1(13-73)$} & \multicolumn{2}{|l|}{$43.4 \pm 12.0(14-65)$} & \multicolumn{2}{|c|}{$45.3 \pm 12.0(21-70)$} & \multicolumn{2}{|l|}{$40.5 \pm 10.5(20-56)$} \\
\hline Female sex, n (\%) & \multicolumn{2}{|l|}{$37(90)$} & $40(95)$ & & \multicolumn{2}{|l|}{$46(73)$} & \multicolumn{2}{|l|}{$31(97)$} \\
\hline $\begin{array}{l}\text { AQP4-IgG-seropositive } \\
\text { status, } \mathrm{n}(\%)\end{array}$ & \multicolumn{2}{|l|}{$27(66)$} & $28(67)$ & & \multicolumn{2}{|l|}{$41(65)$} & \multicolumn{2}{|l|}{$23(72)$} \\
\hline $\begin{array}{l}\text { Annualized relapse rate in } \\
\text { previous } 2 y\end{array}$ & \multicolumn{2}{|l|}{$1.5 \pm 0.5$} & $1.4 \pm 0.5$ & & \multicolumn{2}{|l|}{$1.4 \pm 0.6$} & \multicolumn{2}{|l|}{$1.5 \pm 0.7$} \\
\hline $\begin{array}{l}\text { Annualized relapse rate } \\
\text { during the double-blind period }\end{array}$ & \multicolumn{2}{|c|}{$0.11(0.05-0.21)$} & $0.32(0.19-0.51)$ & & \multicolumn{2}{|l|}{$0.17(0.10-0.26)$} & \multicolumn{2}{|l|}{$0.41(0.24-0.67)$} \\
\hline \multicolumn{9}{|c|}{ Relapse prevention efficacy (vs placebo) } \\
\hline AQP4-IgG (+ and -) & \multicolumn{4}{|c|}{$\mathrm{HR}=0.38(0.16-0.88)$} & \multicolumn{4}{|c|}{$\mathrm{HR}=0.45(0.23-0.89)$} \\
\hline AQP4-IgG (+) & \multicolumn{4}{|c|}{$H R=0.21(0.06-0.75)$} & $H R=0.26(0.11-0$ & 63), & & \\
\hline AQP4-IgG (-) & $\mathrm{HR}=0.66$ & $-2.24)$ & & & $H R=1.19(0.30-4$ & & & \\
\hline $\begin{array}{l}\text { AEs in the double-blind period } \\
\text { (safety population) }\end{array}$ & $\begin{array}{l}\text { Patients, } \\
\text { n (\%) }\end{array}$ & $\begin{array}{l}\text { Events }(95 \% \mathrm{Cl}) \text {, } \\
\mathrm{n} / 100 \mathrm{pt}-\mathrm{y}\end{array}$ & $\begin{array}{l}\text { Patients, } \\
\text { n (\%) }\end{array}$ & $\begin{array}{l}\text { Events }(95 \% \mathrm{Cl}) \\
\mathrm{n} / 100 \mathrm{pt}-\mathrm{y}\end{array}$ & Patients, n (\%) & $\begin{array}{l}\text { Events }(95 \% \mathrm{Cl}) \\
\mathrm{n} / 100 \mathrm{pt}-\mathrm{y}\end{array}$ & Patients, n (\%) & $\begin{array}{l}\text { Events }(95 \% \mathrm{Cl}) \\
\mathrm{n} / 100 \mathrm{pt}-\mathrm{y}\end{array}$ \\
\hline Infection & $28(68)$ & $\begin{array}{l}132.5 \\
(108.2-160.5)\end{array}$ & $26(62)$ & $149.6(120.1-184.1)$ & $34(54)$ & $99.8(82.4-119.8)$ & $14(44)$ & $162.6(125.8-206.9)$ \\
\hline Serious infection & $2(5)$ & $2.6(0.3-9.2)$ & $3(7)$ & $5.0(1.0-14.7)$ & $6(10)$ & $5.2(1.9-11.3)$ & $3(9)$ & $9.9(2.7-25.2)$ \\
\hline Injection-related reaction & $5(12)$ & $21.7(12.6-34.7)$ & $2(5)$ & $3.4(0.4-12.1)$ & $8(13)$ & $13.9(7.9-22.6)$ & $5(16)$ & $17.3(6.9-35.5)$ \\
\hline Anaphylactic reaction & 0 & 0 & 0 & 0 & 0 & 0 (NE-3.2) & 0 & 0 (NE-9.1) \\
\hline
\end{tabular}




\section{Study funding}

This study was funded by Chugai Pharmaceutical Co, Ltd. Medical and medical writing support was provided by ApotheCom, UK, and was funded by Chugai Pharmaceutical Co, Ltd.

\section{Disclosure}

K. Fujihara has received grants from the Ministry of Education of Japan, Ministry of Health, Welfare and Labor of Japan, Alexion Pharmaceuticals, Chemo-Sero-Therapeutic Research Institute, Teva, Teijin, and Genzyme Japan; received grants and personal fees from Chugai Pharmaceutical Co, Ltd, Bayer, Biogen, Mitsubishi Tanabe, Ono, Nihon Pharmaceutical, and Asahi Kasei; and received personal fees from Novartis, Merck Serono, MedImmune, Eisai, Astellas, Takeda, Daiichi Sankyo, and Cosmic Corporation. J.L. Bennett holds patents for compositions and methods for the treatment of neuromyeltis optica and novel blocking monoclonal therapy for neuromyelitis optica; has consulted for Frequency Therapeutics, Roche, Viela Bio, AbbVie, Clene Nanomedicine, Alexion Pharmaceuticals, EMDSerono, Chugai Pharmaceutical Co, Ltd, Reistone, and Genentech; received research support from Mallinckrodt Pharmaceuticals, NIH, Novartis, and Guthy-Jackson Foundation; and receives license fee and royalty payments for aquaporumab. J. de Seze has received grants and personal fees from Roche; received personal fees from Chugai Pharmaceutical Co, Ltd; and served on advisory boards and expert committees for the clinical trial conducted by Chugai Pharmaceutical Co, Ltd. M. Haramura is an employee of Chugai Pharmaceutical Co., Ltd. I. Kleiter has received personal fees from Alexion Pharmaceuticals, Bayer, Biogen, Celgene, IQVIA, Novartis, Merck, Mylan, Roche, Sanofi Genzyme, grants and personal fees from Chugai Pharmaceutical Co, Ltd, and grants from Diamed. B.G. Weinshenker holds a patent for and receives royalties from an NMO-IgG for diagnosis of neuromyelitis optica from RSR Ltd, Oxford University, Hospices Civil de Lyon, and MVZ Labor PD Dr. Volkmann und Kollegen GbR.; is an adjudication committee member of MedImmune Pharmaceuticals and Alexion Pharmaceuticals; consults for Chugai Pharmaceutical Co., Ltd and Mitsubishi Tanabe; and served on the editorial board of the Canadian Journal of Neurological Sciences and Turkish Journal of Neurology. T. Yamamura has served on scientific advisory boards for Biogen, Takeda, Ono, Sumitomo Dainippon, Novartis, and Chugai Pharmaceutical Co, Ltd; received research grants from Chugai Pharmaceutical Co, Ltd, Biogen, Novartis, Takeda, Teva, and Nihon Pharmaceutical; and received speaker honoraria from Chugai Pharmaceutical Co, Ltd, Ono, Takeda, Biogen, Sumitomo Dainippon, Mitsubishi Tanabe, Human Metabolome Technologies, Bayer, Japan Blood Products Organization, Otsuka, Kissei, Novartis, and Daiichi Sankyo. Go to Neurology.org/NN for full disclosures.

\section{Publication history}

Received by Neurology: Neuroimmunology \& Neuroinflammation April 1, 2020. Accepted in final form June 5, 2020.
Appendix Authors

\begin{tabular}{|c|c|c|}
\hline Name & Location & Contribution \\
\hline $\begin{array}{l}\text { Kazuo } \\
\text { Fujihara, MD }\end{array}$ & $\begin{array}{l}\text { Department of Multiple } \\
\text { Sclerosis Therapeutics, } \\
\text { Fukushima Medical } \\
\text { University School of } \\
\text { Medicine and Multiple } \\
\text { Sclerosis and } \\
\text { Neuromyelitis Optica } \\
\text { Center, Southern } \\
\text { TOHOKU Research } \\
\text { Institute for } \\
\text { Neuroscience, Koriyama, } \\
\text { Japan }\end{array}$ & $\begin{array}{l}\text { Design and } \\
\text { conceptualization of the } \\
\text { review, manuscript } \\
\text { drafting, and critical } \\
\text { revision of the manuscript } \\
\text { for important intellectual } \\
\text { content }\end{array}$ \\
\hline
\end{tabular}

\begin{tabular}{lll}
\hline Jeffrey L. & Departments of & $\begin{array}{l}\text { Design of the review and } \\
\text { Bennett, MD, }\end{array}$ \\
PhD & Neurolical revision and & manuscript for important \\
Ophthalmology, & intellectual content \\
& $\begin{array}{l}\text { Programs in } \\
\text { Neuroscience and }\end{array}$ & \\
Immunology, School of & \\
Medicine, University of & \\
Colorado, Aurora & \\
\hline
\end{tabular}

\begin{tabular}{lll}
\hline Jerome de & Department of & $\begin{array}{l}\text { Design of the review and } \\
\text { Seze, MD, PhD }\end{array}$ \\
& $\begin{array}{l}\text { Neurolical revision of the } \\
\text { Hautepierre, Strasbourg } \\
\text { Cedex, France }\end{array}$ & $\begin{array}{l}\text { manuscript for important } \\
\text { intellectual content }\end{array}$ \\
\hline
\end{tabular}

Masayuki Chugai Pharmaceutical Design of the review and
Haramura, Co., Ltd, Tokyo, Japan critical revision of the PhD manuscript for important intellectual content

\begin{tabular}{lll}
\hline $\begin{array}{l}\text { Ingo Kleiter, } \\
\text { MD }\end{array}$ & $\begin{array}{l}\text { Department of } \\
\text { Neurology, St. Josef } \\
\text { Hospital, Ruhr-University } \\
\text { Bochum, Germany }\end{array}$ & $\begin{array}{l}\text { Design of the review and } \\
\text { critical revision of the } \\
\text { manuscript for important } \\
\text { intellectual content }\end{array}$ \\
\hline $\begin{array}{l}\text { Brian G. } \\
\text { Weinshenker, } \\
\text { MD }\end{array}$ & $\begin{array}{l}\text { Department of } \\
\text { Neurology, Mayo Clinic, } \\
\text { Rochester, MN }\end{array}$ & $\begin{array}{l}\text { Design of the review and } \\
\text { critical revision of the } \\
\text { manuscript for important } \\
\text { intellectual content }\end{array}$ \\
\hline $\begin{array}{l}\text { Delene Kang } \\
\text { Tabasum } \\
\text { Mughal, PhD }\end{array}$ & ApotheCom, London, UK & $\begin{array}{l}\text { Critical revision of the } \\
\text { manuscript for important } \\
\text { intellectual content }\end{array}$ \\
\hline $\begin{array}{l}\text { Takashi } \\
\text { Yamamura, } \\
\text { MD, PhD }\end{array}$ & $\begin{array}{l}\text { Department of } \\
\text { Immunology, National } \\
\text { Institute of Neuroscience, }\end{array}$ & $\begin{array}{l}\text { Design of the review and } \\
\text { critical revision of the } \\
\text { manuscript for important } \\
\text { intellectual content }\end{array}$ \\
$\begin{array}{l}\text { National Center of } \\
\text { Neurology and Psychiatry, }\end{array}$ & $\begin{array}{l}\text { Critical revision of the } \\
\text { intellectual content }\end{array}$ \\
Tokyo, Japan & \\
\hline
\end{tabular}

\section{References}

1. Tanaka T, Narazaki M, Kishimoto T. IL-6 in inflammation, immunity, and disease. Cold Spring Harb Perspect Biol 2014;6:a016295.

2. Wingerchuk DM, Banwell B, Bennett JL, et al. International consensus diagnostic criteria for neuromyelitis optica spectrum disorders. Neurology 2015;85:177-189.

3. Zekeridou A, Lennon VA. Aquaporin-4 autoimmunity. Neurol Neuroimmunol Neuroinflamm 2015;2:e110. doi: 10.1212/NXI.0000000000000110.

4. Papadopoulos MC, Bennett JL, Verkman AS. Treatment of neuromyelitis optica: state-of-the-art and emerging therapies. Nat Rev Neurol 2014;10:493-506.

5. Duan T, Smith AJ, Verkman AS. Complement-independent bystander injury in AQP4-IgG seropositive neuromyelitis optica produced by antibody-dependent cellular cytotoxicity. Acta Neuropathol Commun 2019;7:112.

6. Ataie-Kachoie P, Pourgholami MH, Morris DL. Inhibition of the IL-6 signaling pathway: a strategy to combat chronic inflammatory diseases and cancer. Cytokine Growth Factor Rev 2013;24:163-173.

7. Tanaka T, Kishimoto T. Targeting interleukin-6: all the way to treat autoimmune and inflammatory diseases. Int J Biol Sci 2012;8:1227-1236. 
8. Garbers C, Heink S, Korn T, Rose-John S. Interleukin-6: designing specific therapeutics for a complex cytokine. Nat Rev Drug Discov 2018;17:395-412.

9. Erta M, Quintana A, Hidalgo J. Interleukin-6, a major cytokine in the central nervous system. Int J Biol Sci 2012;8:1254-1266.

10. Feng Q, Wang YI, Yang Y. Neuroprotective effect of interleukin-6 in a rat model of cerebral ischemia. Exp Ther Med 2015;9:1695-1701.

11. Zhang J, Sadowska GB, Chen X, et al. Anti-IL-6 neutralizing antibody modulates blood-brain barrier function in the ovine fetus. FASEB J 2015;29:1739-1753.

12. Weinshenker BG, Wingerchuk DM. Neuromyelitis spectrum disorders. Mayo Clin Proc 2017;92:663-679.

13. Uzawa A, Mori M, Muto M, et al. Benign neuromyelitis optica is rare in Japanese patients. Mult Scler 2015;21:1204-1208.

14. Wingerchuk DM, Lennon VA, Lucchinetti CF, Pittock SJ, Weinshenker BG. The spectrum of neuromyelitis optica. Lancet Neurol 2007;6:805-815.

15. Kitley J, Leite MI, Nakashima I, et al. Prognostic factors and disease course in aquaporin-4 antibody-positive patients with neuromyelitis optica spectrum disorder from the United Kingdom and Japan. Brain 2012;135:1834-1849.

16. Mealy MA, Kessler RA, Rimler Z, et al. Mortality in neuromyelitis optica is strongly associated with African ancestry. Neurol Neuroimmunol Neuroinflamm 2018;5:e468. doi: 10.1212/NXI.0000000000000468.

17. Lennon VA, Wingerchuk DM, Kryzer TJ, et al. A serum autoantibody marker of neuromyelitis optica: distinction from multiple sclerosis. Lancet 2004;364: 2106-2112.

18. Wingerchuk DM, Lennon VA, Pittock SJ, Lucchinetti CF, Weinshenker BG. Revised diagnostic criteria for neuromyelitis optica. Neurology 2006;66:1485-1489.

19. Kowarik MC, Dzieciatkowska M, Wemlinger S, et al. The cerebrospinal fluid immunoglobulin transcriptome and proteome in neuromyelitis optica reveals central nervous system-specific B cell populations. J Neuroinflammation 2015;12:19.

20. Mitsdoerffer M, Kuchroo V, Korn T. Immunology of neuromyelitis optica: a T cell-B cell collaboration. Ann N Y Acad Sci 2013;1283:57-66.

21. Day RE, Kitchen P, Owen DS, et al. Human aquaporins: regulators of transcellular water flow. Biochim Biophys Acta 2014;1840:1492-1506.

22. Jarius S, Franciotta D, Paul F, et al. Cerebrospinal fluid antibodies to aquaporin-4 in neuromyelitis optica and related disorders: frequency, origin, and diagnostic relevance. J Neuroinflammation 2010;7:52.

23. Bennett JL, Lam C, Kalluri SR, et al. Intrathecal pathogenic anti-aquaporin-4 antibodies in early neuromyelitis optica. Ann Neurol 2009;66:617-629.

24. Jarius S, Ruprecht K, Wildemann B, et al. Contrasting disease patterns in seropositive and seronegative neuromyelitis optica: a multicentre study of 175 patients. J Neuroinflammation 2012;9:14.

25. Jarius S, Ruprecht K, Kleiter I, et al. MOG-IgG in NMO and related disorders: a multicenter study of 50 patients. Part 2: epidemiology, clinical presentation, radiological and laboratory features, treatment responses, and long-term outcome. J Neuroinflammation 2016;13:280.

26. Shimizu F, Schaller KL, Owens GP, et al. Glucose-regulated protein 78 autoantibody associates with blood-brain barrier disruption in neuromyelitis optica. Sci Transl Med 2017;9:eaai9111.

27. Nytrova P, Potlukova E, Kemlink D, et al. Complement activation in patients with neuromyelitis optica. J Neuroimmunol 2014;274:185-191.

28. Tradtrantip L, Yao X, Su T, Smith AJ, Verkman AS. Bystander mechanism for complement-initiated early oligodendrocyte injury in neuromyelitis optica. Acta Neuropathol 2017;134:35-44.

29. Yao X, Verkman AS. Complement regulator CD59 prevents peripheral organ injury in rats made seropositive for neuromyelitis optica immunoglobulin G. Acta Neuropathol Commun 2017;5:57.

30. Zamvil SS, Spencer CM, Baranzini SE, Cree BAC. The gut microbiome in neuromyelitis optica. Neurotherapeutics 2018;15:92-101.

31. Omenetti S, Pizarro TT. The Treg/Th17 Axis: a dynamic balance regulated by the gut microbiome. Front Immunol 2015;6:639.

32. Uzawa A, Mori M, Masuda $\mathrm{H}$, et al. Interleukin-6 analysis of 572 consecutive CSF samples from neurological disorders: a special focus on neuromyelitis optica. Clin Chim Acta 2017;469:144-149.

33. Wang H, Wang K, Zhong $\mathrm{X}$, et al. Notable increased cerebrospinal fluid levels of soluble interleukin-6 receptors in neuromyelitis optica. Neuroimmunomodulation 2012;19:304-308.

34. Uzawa A, Mori M, Arai $\mathrm{K}$, et al. Cytokine and chemokine profiles in neuromyelitis optica: significance of interleukin-6. Mult Scler 2010;16:1443-1452.

35. Uchida T, Mori M, Uzawa A, et al. Increased cerebrospinal fluid metalloproteinase-2 and interleukin- 6 are associated with albumin quotient in neuromyelitis optica: their possible role on blood-brain barrier disruption. Mult Scler 2017;23:1072-1084.
36. Matsushita $\mathrm{T}$, Tateishi $\mathrm{T}$, Isobe $\mathrm{N}$, et al. Characteristic cerebrospinal fluid cytokine/ chemokine profiles in neuromyelitis optica, relapsing remitting or primary progressive multiple sclerosis. PLoS One 2013;8:e61835.

37. Icoz S, Tuzun E, Kurtuncu M, et al. Enhanced IL-6 production in aquaporin-4 antibody positive neuromyelitis optica patients. Int J Neurosci 2010;120:71-75.

38. Barros PO, Cassano T, Hygino J, et al. Prediction of disease severity in neuromyelitis optica by the levels of interleukin (IL)-6 produced during remission phase. Clin Exp Immunol 2016;183:480-489.

39. Uzawa A, Mori M, Ito M, et al. Markedly increased CSF interleukin-6 levels in neuromyelitis optica, but not in multiple sclerosis. J Neurol 2009;256:2082-2084.

40. Uzawa A, Mori M, Sawai S, et al. Cerebrospinal fluid interleukin-6 and glial fibrillary acidic protein levels are increased during initial neuromyelitis optica attacks. Clin Chim Acta 2013;421:181-183.

41. Uzawa A, Mori M, Sato Y, Masuda S, Kuwabara S. CSF interleukin-6 level predicts recovery from neuromyelitis optica relapse. J Neurol Neurosurg Psychiatry 2012;83:339-340.

42. Chihara N, Aranami T, Sato W, et al. Interleukin 6 signaling promotes anti-aquaporin 4 autoantibody production from plasmablasts in neuromyelitis optica. Proc Natl Acad Sci USA 2011;108:3701-3706.

43. Kowarik MC, Astling D, Gasperi C, et al. CNS Aquaporin-4-specific B cells connect with multiple B-cell compartments in neuromyelitis optica spectrum disorder. Ann Clin Transl Neurol 2017;4:369-380.

44. Dienz O, Eaton SM, Bond JP, et al. The induction of antibody production by IL-6 is indirectly mediated by IL-21 produced by CD4+ T cells. J Exp Med 2009;206:69-78.

45. Dos Passos GR, Sato DK, Becker J, Fujihara K. Th17 cells pathways in multiple sclerosis and neuromyelitis optica spectrum disorders: pathophysiological and therapeutic implications. Mediators Inflamm 2016;2016:5314541.

46. Wang HH, Dai YQ, Qiu W, et al. Interleukin-17-secreting T cells in neuromyelitis optica and multiple sclerosis during relapse. J Clin Neurosci 2011;18:1313-1317.

47. Varrin-Doyer M, Spencer CM, Schulze-Topphoff U, et al. Aquaporin 4-specific T cells in neuromyelitis optica exhibit a Th17 bias and recognize Clostridium ABC transporter. Ann Neurol 2012;72:53-64.

48. Takeshita Y, Obermeier B, Cotleur AC, et al. Effects of neuromyelitis optica-IgG at the blood-brain barrier in vitro. Neurol Neuroimmunol Neuroinflamm 2017;4:e311. doi: 10.1212/NXI.0000000000000311.

49. Fujihara K, Sato DK, Nakashima I, et al. Myelin oligodendrocyte glycoprotein immunoglobulin G-associated disease: an overview. Clin Exp Neuroimmunol 2018;9: 48-55.

50. Kaneko K, Sato DK, Nakashima I, et al. Myelin injury without astrocytopathy in neuroinflammatory disorders with MOG antibodies. J Neurol Neurosurg Psychiatry 2016;87:1257-1259.

51. Cree BAC, Bennett JL, Kim HJ, et al. Inebilizumab for the treatment of neuromyelitis optica spectrum disorder (N-MOmentum): a double-blind, randomised placebocontrolled phase 2/3 trial. Lancet 2019;394:1352-1363.

52. Pittock SJ, Berthele A, Fujihara K, et al. Eculizumab in aquaporin-4-positive neuromyelitis optica spectrum disorder. N Engl J Med 2019;381:614-625.

53. Yamamura T, Kleiter I, Fujihara K, et al. Trial of satralizumab in neuromyelitis optica spectrum disorder. N Engl J Med 2019;381:2114-2124.

54. Ringelstein M, Ayzenberg I, Harmel J, et al. Long-term therapy with interleukin 6 receptor blockade in highly active neuromyelitis optica spectrum disorder. JAMA Neurol 2015;72:756-763.

55. Lauenstein AS, Stettner M, Kieseier BC, Lensch E. Treating neuromyelitis optica with the interleukin-6 receptor antagonist tocilizumab. BMJ Case Rep 2014;2014: bcr2013202939.

56. Araki M, Matsuoka T, Miyamoto K, et al. Efficacy of the anti-IL-6 receptor antibody tocilizumab in neuromyelitis optica: a pilot study. Neurology 2014;82:1302-1306.

57. Kieseier BC, Stuve O, Dehmel T, et al. Disease amelioration with tocilizumab in a treatment-resistant patient with neuromyelitis optica: implication for cellular immune responses. JAMA Neurol 2013;70:390-393.

58. Ayzenberg I, Kleiter I, Schroder A, et al. Interleukin 6 receptor blockade in patients with neuromyelitis optica nonresponsive to anti-CD20 therapy. JAMA Neurol 2013; 70:394-397.

59. Araki M, Aranami T, Matsuoka T, Nakamura M, Miyake S, Yamamura T. Clinical improvement in a patient with neuromyelitis optica following therapy with the antiIL-6 receptor monoclonal antibody tocilizumab. Mod Rheumatol 2013;23:827-831.

60. Harmel J, Ringelstein M, Ingwersen J, et al. Interferon-beta-related tumefactive brain lesion in a Caucasian patient with neuromyelitis optica and clinical stabilization with tocilizumab. BMC Neurol 2014;14:247.

61. Traboulsee A, Greenberg B , Bennett JL, et al. Safety and efficacy of satralizumab monotherapy in neuromyelitis optica spectrum disorder: a randomised, double-blind, multicentre, placebo-controlled phase 3 trial. Lancet Neurol 2020;19:402-412. 


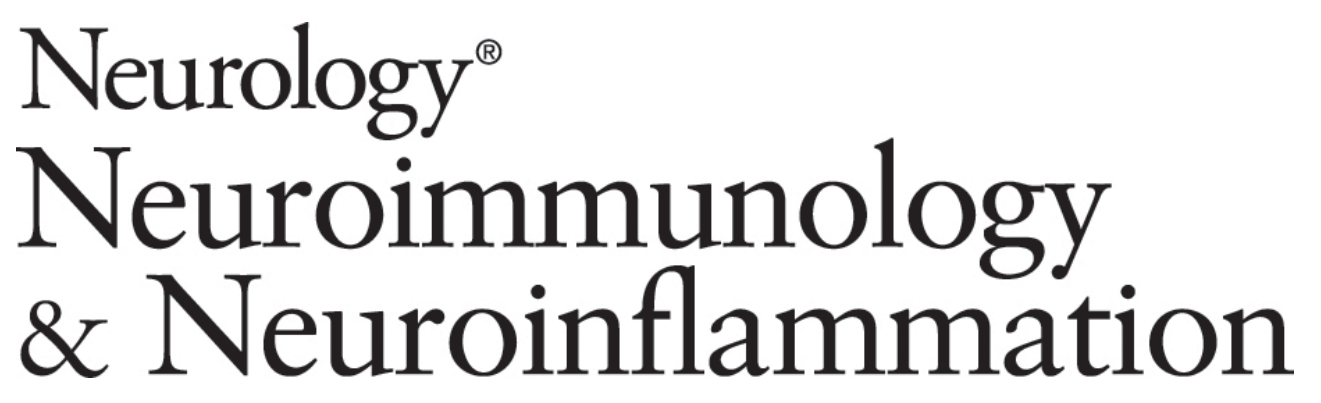

Interleukin-6 in neuromyelitis optica spectrum disorder pathophysiology

Kazuo Fujihara, Jeffrey L. Bennett, Jerome de Seze, et al.

Neurol Neuroimmunol Neuroinflamm 2020;7;

DOI 10.1212/NXI.0000000000000841

This information is current as of August 20, 2020

Neurol Neuroimmunol Neuroinflamm is an official journal of the American Academy of Neurology.

Published since April 2014, it is an open-access, online-only, continuous publication journal. Copyright

Copyright $\odot 2020$ The Author(s). Published by Wolters Kluwer Health, Inc. on behalf of the American

Academy of Neurology.. All rights reserved. Online ISSN: 2332-7812.

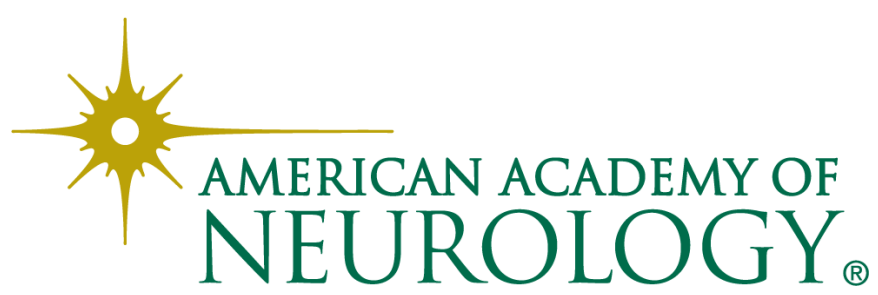




\section{Updated Information \& Services}

References

Citations

Subspecialty Collections

Permissions \& Licensing

Reprints including high resolution figures, can be found at: http://nn.neurology.org/content/7/5/e841.full.html

This article cites 60 articles, 9 of which you can access for free at: http://nn.neurology.org/content/7/5/e841.full.html\#\#ref-list-1

This article has been cited by 4 HighWire-hosted articles: http://nn.neurology.org/content/7/5/e841.full.html\#\#otherarticles

This article, along with others on similar topics, appears in the following collection(s):

\section{All Spinal Cord}

http://nn.neurology.org//cgi/collection/all_spinal_cord Autoimmune diseases

http://nn.neurology.org//cgi/collection/autoimmune_diseases Cerebrospinal Fluid

http://nn.neurology.org//cgi/collection/cerebrospinal_fluid

Devic's syndrome

http://nn.neurology.org//cgi/collection/devics_syndrome

Optic nerve

http://nn.neurology.org//cgi/collection/optic_nerve

Information about reproducing this article in parts (figures,tables) or in its entirety can be found online at:

http://nn.neurology.org/misc/about.xhtml\#permissions

Information about ordering reprints can be found online: http://nn.neurology.org/misc/addir.xhtml\#reprintsus

Neurol Neuroimmunol Neuroinflamm is an official journal of the American Academy of Neurology.

Published since April 2014, it is an open-access, online-only, continuous publication journal. Copyright

Copyright $\odot 2020$ The Author(s). Published by Wolters Kluwer Health, Inc. on behalf of the American Academy of Neurology.. All rights reserved. Online ISSN: 2332-7812.

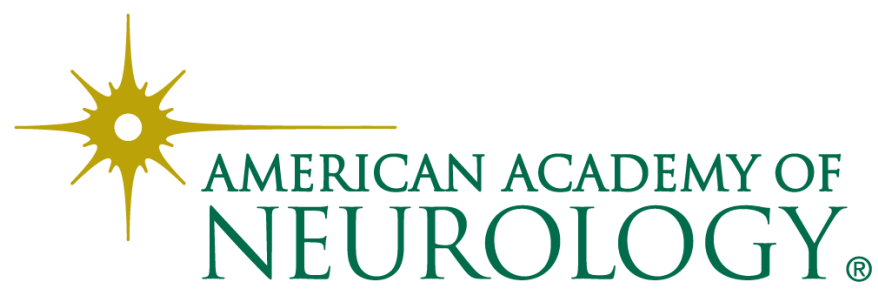

